\title{
1. Social innovation and relational leadership: opening up new perspectives on social change
}

Social innovation, understood as resulting from an interwoven discursivematerial process, could be seen as a driver of social change. Nevertheless, social innovation is not the only possible driver of social change (Light 2011); nor do all socially innovative initiatives necessarily trigger social change. As such, we argue that to become a real driver of social change, social innovation must necessarily be effective and scalable. To better understand how social change comes about and the extent to which processes of social innovation could become drivers of it, theories of leadership offer a new perspective that complements and goes beyond existing studies.

Bringing relational leadership theories to bear on the study of social innovation dovetails with the context-leadership debate addressed by the SOCRISIS project. As we will show empirically in Part III of this book, context - understood as a varying path-dependent and spatio-temporal configuration of constraints and opportunities - shapes how, where and in what form social innovation emerges. At the same time, however, we need agency-based explanations in order to comprehend the capacity of socially innovative initiatives to catalyse collective action in particular ways, specific conjunctures and broader structural contexts. Understanding social change - as driven by context-sensitive dialectical relationships between neighbourhood features and collective agency, materialized through discursive practices and mediated by institutions - opens up new avenues both for analyzing urban and regional development (Moulaert et al. 2016) and for social innovation studies.

In this chapter we review the literature on social innovation, bringing together disruptive theories of social innovation and constructionist theories of relational leadership. In so doing we identify the main challenges for the novel approach to analyzing social change developed theoretically and empirically throughout this book. 


\subsection{SOCIAL INNOVATION: DEFINITION AND THEORIES}

Social innovation has, over the past fifteen years or so, become a buzzword. Various research groups, nonprofits, multilateral organizations and governments have placed the concept at the top of their agendas, most of them presenting the idea as something new. However, social innovation as a concept actually dates back to the beginning of the 19th century. Jessop et al. (2013) distinguish between 'old' theorists of social change, who characterize the period from the end of the 19th century up to the late 1960s, and the 'new lighters' in social innovation analysis, who emerged from the 1970 s onwards. While earlier theorists were more interested in social process dynamics, more recent scholars have focused more on the endsmeans relationship and use to a greater extent a micro-logical, partial or practice-oriented approach. Jessop et al. (2013) argue for the reunification of 'old' social change analysis with the more practice-oriented analysis of the last three decades. The SOCRISIS project approach, linking practiceoriented social innovation initiatives to social change analysis, takes a step in this direction.

As Godin (2012) notes, social innovation has conveyed different meanings over the last two centuries. In its original use it signified socialism; it later came to mean social reform and in the second half of the 20th century has been understood as alternatives to 'established' solutions to social problems or needs. It is in this most recent sense that we refer to social innovation in this book. The emergence of this meaning in the second half of the last century was a political reaction to hegemonic discourses regarding technological innovation. Hence, we understand social innovation as a political concept - that is, one employed for political aims - grounded in the production of alternative solutions (based on alternative discourses and imaginaries) to 'established' market-led forms of regulation and state-supported social reform. Our understanding of social innovation is therefore inspired by its resurrection in Europe in the 1970s and 1980s as a counterhegemonic category that emerged out of late-1960s democratization movements - movements that were concerned with claims such as autonomy, self-governance and participation. This understanding of social innovation contrasts with the New Public Management approach developed by multilateral organizations such as the Organisation for Economic Co-operation and Development (OECD), the World Bank and the European Commission (OECD 2002; European Commission 2010), which emerged in the early 2000s when such institutions began to approach the social dimensions of innovation in a rather reductionist (micro-economic) and apolitical manner. As we will see in 
the next section, this recent neoliberal trend reconnects with the early Schumpeterian spirit of the economic and managerial literature on social innovation studies.

In contrast, our definition of social innovation - as a complex process of introducing alternative solutions that produce systemic changes encompasses three key features that social innovation is related to: a) the satisfaction of alienated human needs; b) the transformation of social relationships and c) the empowerment of citizens (Moulaert et al. 2013). Let us briefly address these three characteristics.

First, during the last three decades social innovation has evolved into a broader field and is currently used to describe many social practices, including time banks, cooperative nursery schools, voluntary welfare services and self-managed social centres. In 2010, Murray et al. (2010: 2) defined social innovation as 'the many ways in which people are creating new and more effective answers to the biggest challenges of our times', a definition echoed by the European Commission. So, here we have the first common feature of the concept, as all contemporary analysts understand it: the satisfaction of human needs. It is for this reason that processes and practices of social innovation are conceived of as a public service.

Second, social innovation is only one type of innovation. Religious, political or economic innovation could be other types (Godin 2012). In the 1940s, for example, economic literature introduced technological innovation as a catchword. Although the term social innovation appeared much earlier than technological innovation, it is now regularly contrasted to this later term, with most authors presenting it as a remedy for the undesired effects of technological innovation (Mulgan 2007). The term social innovation explicitly rejects a technology-focused understanding in favour of a more 'nuanced reading which valorises the knowledge and cultural assets of communities and which foregrounds the creative reconfiguration of social relations' (MacCallum et al. 2009: 2). In this vein, social innovation as a concept is also a reaction to the narrowly economic- and businessoriented interpretations and applications of innovation. Unlike technological, economic, religious or political innovation, social innovation emerges from and reconfigures social relations. Hence, the second key feature of the concept is that social innovation addresses human needs through the transformation of social relations, namely new organizational models, forms of governance, collective action, social learning and so on.

It should be noted that these two features of social innovation - the satisfaction of human needs and the transformation of social relations are widely accepted by all approaches to social innovation today. The European Commission, for example, includes these two features in its definition of social innovation as 'new ideas (products, services and models) that 
simultaneously meet social needs (more effectively than alternatives) and create new social relationships or collaborations' (European Commission 2010: 9). However, the approach of the European Commission is based on social entrepreneurship, which simplifies social innovation to the satisfaction of human needs through social means. In a context in which national states are being weakened and welfare policies retrenched, the European Commission is searching for new sources of economic growth and ways to solve collective problems beyond the state and the market (BEPA 2011). From a neoliberal perspective, this understanding of social innovation is used to justify welfare state retrenchment, the shifting of responsibilities to civil society and arguments claiming that when neither the state nor the market can satisfy social needs, people must be innovative, entrepreneurial and address human needs in a creative 'do-it-yourself' way.

This brings us to the third feature of social innovation according to our understanding: empowerment. The fact that, for the SOCRISIS project, social innovation implies the empowerment of citizens gives an ethical and political element to our definition that distinguishes it from the aforementioned understandings. This implies that not only social but also power relations should be transformed from below.

According to Chambon et al. (1982), social innovation concerns collective actions and social transformations that would lead us from a top-down economy and society to a more bottom-up, creative and participative society. This sentiment is clearly related to the concept of empowerment, understood as citizen's engagement, the development of citizen capabilities and empowering people to solve their collective problems. Empowerment is therefore a process through which citizens strengthen their capacities, trust, awareness and prominence as a part of a group or community. Through this process, power relationships in the social system in which social innovation occurs are transformed to the benefit of minorities, havenots, excluded social groups and even the entire community.

To some extent, the increase in interest in social innovation in both scholarship and policy would not have taken place without the flourishing of multiple innovative social practices across the world. In this context, social innovation is gaining strength as an explanation for new social practices that aim to solve collective problems from below. At the same time, the concept is being used in response to the crisis of the welfare state, invoked in multiple offloading practices that reduce the extent of state action and transfer responsibility (but not power) to civil society. As Davies and Pill (2012) argue, the voluntarism of this laissez-faire strategy is a poor substitute for the public investment required to sustain neighbourhood revitalization in the current economic context. The rise of innovative social practices certainly implies some kind of reordering and a 
relational shift between state, market and community. This shift may be the result of a rollout neoliberal strategy in which market forces set the rules of the game and empower some new actors while disempowering others. Alternatively, rising levels of social innovation may be the expression of a timeless dynamic through which people struggle for empowerment and defend their basic rights from constant challenges. It is these contradictory aspects of the concept that led Swyngedouw (2005) to describe social innovation as 'the Janus face of governance-beyond-the-state'.

\subsubsection{Approaches to Social Innovation}

In general terms, social innovation refers to cooperative processes and practices that are based on citizen involvement, are conceived of as a public service and aim to improve (or make more efficient) existing solutions to social demands. As we have noted, most of the literature on social innovation has taken an economistic approach; nonetheless, there are some approaches to the concept that stem from other disciplines, and even interdisciplinary endeavours. Up to a certain point, all these different conceptualizations share some common features: the use of formal and informal practices, their interdependent relationship with public and private bodies, the cooperative work of local communities and, in some cases, their capability to produce institutional shifts (Martínez 2011). Let us now dig into some of the differences between these approaches.

The economistic approach, drawing on Schumpeter (1974), links social innovation to an economic subject (an entrepreneur) who designs, produces and leads to market new ideas, services or processes that open a new economic paradigm. One of the most prominent authors of this approach, Geoff Mulgan (2006), states that individual entrepreneurs, who always have a personal motivation, lead social innovation. Schumpeter closely linked innovation processes with economic crises, which makes his arguments highly relevant to the main purpose of this book. According to Schumpeter, economic crises, such as the Panic of 1873 in Europe and North America, are something natural in a capitalist system. In order to open up a new economic cycle following a crisis, something new is required: a new product, a new system of production or a new organizational model. In other words, an innovation is needed. Much of the scholarship drawing on Schumpeter's view holds that adding the word 'social' to the term 'innovation' implies that such innovations aim to solve a social demand that is not being properly satisfied by either the market or the state (Mulgan et al. 2007). Social innovation, from this point of view, refers to 'innovative activities and services that are motivated by the goal of meeting a social need and that are predominantly diffused through organizations 
whose primary purposes are social' (Mulgan 2006: 146). According to Bassi (2011), this is a pragmatic definition that emphasizes the role of the single individual who, when faced with a social need, finds new ways to meet it through innovative methods.

An approach to social innovation that has much in common with the economistic view is that stemming from management science. The study of the relationship between management, innovation and society is not new; Peter Drucker (1993) focused on the role of society in managerial processes of innovation in the early 1990s. From this perspective, social innovation is defined as 'a novel solution to a social problem that is more effective, efficient, sustainable or just than existing solutions' (Phillis et al. 2008: 36). As we can see, this definition highlights the managerial aspect of social innovation, which constitutes a better solution. Moreover, and in contrast to the economistic approach, such scholarship implies that the benefits gained through social innovation apply to society as a whole rather than to the narrow interests of entrepreneurs. Lastly, as MacCallum et al. (2009) note, much scholarship in this area emphasizes that an increase in social capital would allow economic organizations to either function better or to change, and that this would produce positive effects with respect to social innovation in both the for-profit and nonprofit sectors.

Both economistic and managerial approaches share a view of social innovation as a linear process, suggesting that social innovation could be fostered and managed in an incremental way. In contrast, the following approaches conceive of social innovation as a disruptive and nonlinear process that prompts a shift in either public institutions or power relationships (Martínez 2011). In line with this, MacCallum et al. (2009: 14) remarked that 'the return of social innovation, both in scientific literature and political practice, is demonstrated by the use of the concept as an alternative to the logic of the market ... and it is expressed in terms of solidarity and reciprocity'.

The third perspective on social innovation we introduce - the creative approach - combines elements of both conceptions, depending on how new creations are produced. Mumford (2010) used this approach in his work, which analyzes the personal histories of notable people, leaders' capacities to solve organizational problems and innovations in industrial organizations. According to him, social innovation refers to 'the generation and implementation of new ideas about how people should organize interpersonal activities, or social interactions, to meet one or more common goals' (Mumford 2010: 253). In his view it is key that the development of these ideas creates something new and generates a social change. For him, examples of change are the creation of new kinds of social institutions, the development of new social movements, the creation of new processes and 
procedures for structuring collaborative work and the development of new business practices.

Another approach arises from the field of political science and public administration. From this perspective, social innovation is concerned with changes in the political and institutional system. Most of the contributions from this field are based on the criticism of hierarchical, bureaucratic and top-down forms of government; they explore how new forms of social innovation foster (among other things) institutional change in terms of territorial decentralization, participatory democracy and transparency (Moulaert et al. 2010). Going beyond the Janus face of governance mechanisms (Swyngedouw 2005), this approach combines a number of different features attributed to social innovation. Social innovation encompasses bottom-up practices and processes emerging from below (which sometimes contest the state) that trigger institutional changes in public policies. However, it also includes several forms of co-provision (by the state and civil society organizations) of public services (Prestoff and Brandsen 2008) through top-down governance and, most intriguingly, the bottomlinked approach suggested by García (2006). As Eizaguirre et al. argue, despite the fact that dominant discourses on 'good governance' emphasize the beneficial consequences of social and political consensus, many social innovations and citizens' practices are based on counterhegemonic ideals and use conflict in order to achieve social and institutional changes (Eizaguirre et al. 2012).

The fifth field that invokes the concept of social innovation is geography. As we have argued (and as MacCallum et al. (2009) have also reported), in Western Europe, North America and Latin America, urban neighbourhoods have been the spatial focus of territorial development. Drawing upon area-based analysis, this approach focuses on social innovation as a territorial process (Van Dyck and Van den Broeck 2013) - as a transformer of spatial relations. Using this approach, MacCallum et al. (2009: 12) define social innovation as 'the satisfaction of alienated human needs through the transformation of social relations: transformations which improve the governance systems that guide and regulate the allocation of goods and services meant to satisfy those needs, and which establish new governance structures and organizations'. As such, this approach shares some similarities with the approach prominent in the political science and public administration literatures. This scholarship argues that needs satisfaction and the provision of assets for development in deprived neighbourhoods cannot be separated, either for the purpose of analyzing past local socioeconomic development trajectories or for the construction of alternatives for the present and the future (Moulaert et al. 2010). In other words, in a highly historical and geographical manner, 
this approach highlights the importance of context and path dependency for understanding both how social innovation practices emerge and how they may become processes of social change. At the same time, this is a community-based approach concerned with a whole range of problems of exclusion, deprivation, alienation and lack of wellbeing, as well as with those actions that contribute positively to significant human progress and development (Moulaert et al. 2013). In this sense, this perspective clearly draws upon an ontological and ethical position that incorporates a social justice lens, and thus also advocates for its pursuit (Moulaert et al. 2005). Lastly, this perspective holds that the empowerment of local populations is a precondition for democratic governance (Novy and Leubolt 2005).

The final approach to social innovation is the systemic approach (Bassi 2011), which draws upon the contributions of various other fields. Grounded in sociology, this approach incorporates different disciplines (such as political science, geography and the humanities) in a postdisciplinary way; in other words, not only crossing the boundaries between academic disciplines and working beyond the limits of the methodologies of single areas of study, but also moving from research to practice and giving an explicit place to practitioners (Moulaert et al. 2010). In the systemic approach, social innovation is active work toward systemic social change and emphasizes the collective aspect of the process of innovation (Bassi 2011). According to its advocates, social innovation can be defined as 'a complex process of introducing new products, processes or programs that profoundly change the basic routines, resource and authority flows, or beliefs of the social system in which the innovation occurs' (Westley and Antadze 2010: 2). Hence, from this perspective the reason that social innovation has a disruptive nature is that it affects power, routine and beliefs.

The systemic approach is therefore a sociopolitical perspective that deals not only with social change but also with the political dimension of innovation in the sense of conflict and power relationships. From this understanding, the object of interest is not the action of an entrepreneur or a service or product, but rather the entire social ecology that enables the innovation process. Innovation is therefore a process and is contextualized in a local area, as with the geographical approach. Moreover, social innovation aims to profoundly change the basic routines, resources, beliefs and power relationships of the social system in which it occurs. From this point of view, social innovation refers to change in agendas, agency and institutions that lead to a better integration of excluded groups and individuals (Moulaert et al. 2005). Social innovation is therefore a process that aims to trigger a social change. As Westley and Antadze (2010) state, in order to produce this social effect, social innovation processes require a complex interaction between the agency of actors and emerging structural 
opportunities. Some scholars who take this perspective argue that successful social innovations should have both durability and a broad impact. Going beyond the market-based model of social innovation, these authors suggest that demand and supply dynamics are not the sole determinants of the scale and direction of innovative activities. Instead, the discontinuous and emergent properties of innovation must be incorporated in order to explain how processes of scaling social innovation up and out occur.

Later in this chapter we will return to discuss which approach is most useful with respect to the purposes of this book and which ideas might usefully be brought together with theories of relational leadership. In the next section, however, we explore who the protagonists of social innovation initiatives are and what role social organizations play in this process.

\subsubsection{Innovation and Social Organizations}

As we have seen, social innovation can be understood as either a practice or a process. Viewed as a practice, it can be carried out by a person (the social entrepreneur, in Schumpeter's (1974) terms) or an organization, or it can be a collective action involving several citizens and organizations. However, if we think of social innovation as a process, the key issue for study becomes the nature of the relationships between actors, between the innovation and its sociogeographical context and between inputs (path dependency), outputs and outcomes (transformations and social change).

Conceived of as a practice or a process, we may be able to observe how many innovative social practices and processes social organizations are involved in. But we cannot affirm that a specific social organization is socially innovative per se. In other words, although we cannot think of social innovation without social organizations, what defines social innovation within a specific organization is what this organization does and how it does it, rather than what the organization is. Social innovation is not therefore necessarily related to new forms of social organization, but rather to the processes and practices in which new and/or existing social organizations may be involved.

When thinking of innovation as social transformation, we must consider historical precedents in collective action that have addressed social problems in different temporal and geographical contexts. Old and new social movements - understood as 'forms of sustained collective action or challenges, based on common purposes and social solidarities, against or interacting with authorities, opponents or elites' (Tarrow 2011: 9) - have involved ordinary people in some form of organized contention from below, circumventing established structures to foster social change (Martinelli 2010). Nevertheless, third-sector organizations, socially creative entities, 
social economy companies and other nonprofit and voluntary associations have also worked for social transformation in different places and time periods. So, when can we affirm that a social organization is engaging in socially innovative actions? Is there anything really new in contemporary social innovation practices and processes?

According to Martinelli (2010), the bridge between social movements and community-generated social innovation is produced when a contentious action has a socially innovative impact; in other words, when a collective action achieves the three main forms of change described earlier - the satisfaction of human needs, the empowerment of marginalized social groups and the transformation of social and power relations. The same bridge could be applied to different forms of social organizations. Eizaguirre (2013), for instance, analyzes socially creative entities and distinguishes them from new social movements, arguing that socially creative entities do not use strategies of confrontation against public administrations and that they need fewer people in order to be effective. Social innovation is not, therefore, something that pertains to any form of social organization.

Over the past two decades some socially innovative responses to new challenges have been based on new ideas and new forms of cooperation (Moulaert et al. 2010). Regarding the contemporary context, the following four trends or developments help qualify how this is happening.

First, an important transformation is reshaping once distinct social structures, blurring boundaries not only between civil society organizations but also between government, business and nonprofits (Bromley and Meyer 2014).

Second, new forms of urban activism are emerging at the same time that old social organizations are being adapted to the new societal context (Gualini et al. 2016). Some of the following features characterize this new urban activism (Walliser 2013): democratic, horizontal and informal procedures and structures, greater heterogeneity in composition, a high degree of politicization but a marked absence of relations with traditional political organizations and an intensive use of Information and Communications Technology, which facilitates networks between citizens and organizations (Bennet and Segerberg 2012). These new forms of organization, moreover, usually combine reactive strategies of protest and contestation with proactive strategies of incidence and dissidence. The use of pragmatic actions to solve collective problems is, in fact, what links these organizations to social innovation processes and practices.

Third, in many western countries the kind of social problems to be tackled have once again turned to material social needs (poverty, unemployment, housing provision and so on). At the same time, post-materialist 
global problems persist and a claim for better democracy is evident in new movements such as Indignados in Spain or the Occupy Wall Street Movement in the US.

Last but not least, after more than 30 years of neoliberalism, counterhegemonic and emancipatory movements and values are gaining strength across the world (Leitner et al. 2006). In this context, principles of justice espoused in the 1960s are regaining prominence, while the negative ethics of difference is being transformed into a positive ethics of cooperation and synergy among citizens and communities (MacCallum et al. 2009).

To sum up, not all instances of contemporary collective action are responding to contemporary crises in a socially innovative way. Some organizations are characterized by new structures, procedures and strategies that are likely to foster socially innovative solutions, while others remain trapped in old paradigms. Social innovation is something beyond nonprofit organizations delivering public services; it implies new responses to current social needs that are based on citizens' empowerment and shifting social relations. Social innovation is, furthermore, distinct from contestation. Although it is perfectly compatible with protest and with action against the state, social innovation always results in the implementation of pragmatic solutions to current social problems. There is no doubt, however, that in contemporary society segments of civil society are characterized by their search for new, self-organized solutions to complex problems.

Having analyzed different approaches to social innovation, its meaning and practices, we now turn to theories of leadership in order to see how agency-based explanations could be usefully employed in social innovation studies to better understand how social change happens.

\subsection{RELATIONAL LEADERSHIP THEORIES}

New forms of leadership have emerged to address the consequences of the economic and social crises, along with a widespread crisis of political and institutional representation currently afflicting many western countries. ${ }^{1}$ In fact, many of the social innovation practices and processes described earlier in this chapter are linked to new forms of distributed, shared, collaborative and collective leadership (Parés et al. 2014a). Drawing upon a review of relational leadership approaches, ${ }^{2}$ in the following sections we will show that the study of leadership may be useful in understanding how local responses to contemporary crises are (or are not) produced, sustained and spread. 


\subsubsection{Approaches to Relational Leadership}

Although leadership studies have traditionally understood their subject as an individual quality, there is an increasing awareness that leadership is not the result of an individual acting alone. In fact, the rapid advancement of technology is changing and challenging the way we consume media, organize data and communicate with each other - a development with significant consequences for the understanding and provision of leadership (Baker 2014). In today's complex environment, new forms of leadership are increasingly needed. Relationality refers to the theoretical understanding that self and other are inseparable and coevolve in ways that must be accounted for (Ospina and Foldy 2010). As we will see, a relational approach to leadership studies is helpful to understand these new forms of leadership.

Modernist assumptions privileging the individual dimension of leadership have focused their attention on the characteristics and attributes that people require to become a good leader. A postmodernist stance, in contrast, understands leadership not as something that pertains to a particular individual but as something that is collective, and is therefore a quality of groups. In this vein, and using a variety of approaches, recent literature on leadership has conceived of and analyzed it as something relational (UhlBien 2006). Leadership scholars are increasingly interested in exploring this relational dimension. For example, scholars of transformational leadership, neo-charismatic leadership and leader-member exchange theory (LMX) are interested in the quality of the leader-follower relationship (Ospina and Hittleman 2011). Others have looked beyond the leader-follower dyad to consider collective relationships, such as distributed or shared forms of leadership, while some authors are now developing a followership theory, recognizing that leadership, as something relational and dialectical, can flow in all directions (Uhl-Bien et al. 2014).

According to Uhl-Bien and Ospina (2012), studies of relational leadership today fall somewhere between two radically different perspectives. On the one hand, an entity perspective considers traits, behaviours and actions of individuals or group members as they engage in interpersonal relationships to influence one another. The 'entity approach' to leadership thus examines relationship-oriented behavioural styles. Examples of theories taking this perspective are LMX theory, charismatic theories of leadership and social identity leadership theory. All these theories see relational leadership as a trend (Ospina and Foldy 2010). On the other hand, a constructionist perspective considers processes of social construction and emergent practices that reflect common understandings through which leadership gains legitimacy and produces outcomes (Uhl-Bien and Ospina 2012). 
This perspective is attentive not only to relationships between individuals but also to their embeddedness in a broader system and to the processes that help to define and constitute such relationships. Therefore, relational leadership is not viewed as a trend but as a lens (Ospina and Foldy 2010). To date, the work of entity and constructionist scholars has developed in parallel, without much dialogue between them.

Leadership has been studied in depth by various disciplines, ranging from the arts and humanities through the social sciences to more applied perspectives, and most of the work - as with research into social innovation crosses disciplinary lines (Harvey and Riggio 2011). Some disciplines more than others have, however, advocated a relational approach. In sociology, for example, scholars have made a huge contribution to understanding leadership as a relational process in which actors (individual or collective) are socially embedded. Seeing leadership through an explicitly sociological lens in fact challenges the dominant assumptions of the individual and collective versions of the entity perspective. In this view, relational leadership is neither a type of leadership nor a trend. Rather, it is intrinsically relational and social in nature, the result of shared meaning-making and rooted in context (Ospina and Hittleman 2011).

The evolution towards relational approaches is also evident in management studies. Management-oriented leadership theories have focused on the behaviour of leaders as engineering effectiveness from the 1950s through to the 1970 s. In the late 1970 s, understanding the leader as strategist shifted to considering the leader as mentor, thus moving from engineering outcomes to a more relationship-based approach (Riggio 2011). New theories viewed leaders as catalysts for organizational outcomes working through the care, coaching and development of followers. Pathgoal theory views the leader as a facilitator or coach (House 1971; 1996), LMX theory claims that effective leadership is determined by the quality of the interaction between the leader and a particular group of followers (Graen and Uhl-Bien 1995) and transformational leadership theory focuses on the qualities of particularly effective leaders who are able to inspire, challenge and develop followers in order to obtain extraordinary levels of follower commitment and performance (Bass and Riggio 2006). Although these new managerial leadership theories were focused on the relationships between leaders and followers, they continued to see leadership as something carried out by leaders. They remained focused, therefore, on how leaders engineer outcomes, but through the development of positive relationships with followers.

Recent literature reflects a debate between leader-centred and followercentred approaches. From a leader-centred perspective, followers are recipients or moderators of leader influence over outcomes, while from a 
follower-centred perspective, followers construct leaders and leadership. In contrast, a relational view suggests that followers engage with leaders in a process of mutual influence. Thus, new followership theories can also be divided into two perspectives. In the first, followership is a position; a rank. This is a role-based approach that simply reverses the lens in leadership research, considering how followers influence leader attitudes, behaviours and outcomes. In the second, a constructionist perspective proposes followership and leadership as co-constructed in social and relational interactions among people (Uhl-Bien et al. 2014).

This debate is not new. Although traditionally little attention has been paid to followership in leadership research, the leader-centred approach has been highly criticized in recent decades. Goleman (1995), for instance, argued that effective leaders must have good 'people skills' and be empathic and emotionally intelligent. Pearce and Conger (2003) focused on new forms of shared leadership, while complexity leadership theory argues that leadership emerges from the complex interplay of individuals in a group or organization, taking into account the particular context and producing adaptive outcomes. According to this last view, leadership involves the collective efforts of multiple individuals to learn, adapt and innovate in response to changing conditions (Uhl-Bien et al. 2007).

Relational leadership theories are not only concerned with the analysis of leader-follower relations, however. There is an increasing movement in leadership studies, known as 'leadership-as-practice' (L-A-P), which proposes that leadership emerges from social practices. Especially significant here is the 'leaderful' approach put forward by Raelin (2010). He argues that even though democratic leadership could be understood as leaderless - there is no need for a leader - it cannot be devoid of leadership. Rather than leaderless, democratic leadership is a form of collective and concurrent leadership. Hence, democratic leadership does not need single leaders (Raelin 2014) but it can produce organizations or groups full of leadership, as it requires full participation in leadership and decisionmaking at all levels of an organization and in multiple decision processes. In other words, democratic leadership is a leaderful practice (Raelin 2011). In this understanding, leadership - a shared, mutual phenomenon - is reframed as collaborative agency, which invokes the inseparable connection between leadership and agency.

Lastly, from a political science perspective, leadership can also be understood in relationship with power (Provizer 2011). According to Burns (1978), we should see leadership and power not as things but as relationships. Leadership, in fact, is a key concept (or process) for understanding societies' exercise of choice in particular historical and geographical contexts. Leadership also explains who gets what, when, how and why - or 
rather, in Lasswell's (1936) terms, politics. Leadership could be analyzed as a relationship of power wherein followers are mobilized for a purpose (Nye 2008), but it could also be interpreted as a process through which power relationships are challenged and transformed. If leadership is related to the concept of choice and to the idea of power as multilayered participation in the making of decisions regarding the fulfilment of human needs, then there is no doubt that leadership is a political concept.

This sociopolitical dimension of leadership can be linked to the systemic approach to social innovation introduced earlier in this chapter. This perspective, as we have seen, highlights not only the social changes produced by social innovation processes but also their political dimension in terms of conflict and power relationships. Drawing on this view, and taking into account the entire social ecology that enables an innovation process, the analysis of leadership in constructionist terms becomes a key object of study for understanding how successful social innovation processes take place. A new research agenda regarding leadership and social innovation must therefore investigate, for example, the extent to which social innovation is effective when collective leadership emerges as part of that process.

\subsubsection{Leadership, Social Change Organizations and Crisis}

Global crises and their local effects are undoubtedly a driving force of multiple processes of economic, social and political change. Some actors in social and political organizations react to the contemporary situation with adaptive strategies, while others try to be proactive, themselves becoming agents of change. In this context, a particular type of social organization SCOs - attempts to lead and to be protagonists of processes of social change. Following Chetkovich and Kunreuther's (2006: 14) definition, SCOs are small, grassroots, nonprofit organizations that 'aim not only to serve those who have been disadvantaged, but to address systemic problems in a way that will increase the power of marginalized groups, communities or interests'. Working on issues such as poverty, homelessness, evictions, education, immigration and civil rights, these groups use various combinations of advocacy, organizing, community development and service delivery in order to address community problems associated with such issues, engaging their constituents in their work (Ospina and Foldy 2010). These organizations aim to influence key external decision makers who have authority to address the problems affecting the organizations' constituents. SCOs are, moreover, exemplars of striving for ambitious goals amid scarcity and turbulent environments and with few material resources (Ospina et al. 2012). For this reason the study of leadership in SCOs is 
highly pertinent, given that local responses to the current economic crisis are being produced amidst scarcity and in a context of austerity politics.

Focusing on new forms of collective leadership, a challenge for SCOs is addressing the tension between on the one hand being inclusive and developing a democratic process, and on the other making sure that effective action takes place. Following the traditional way of thinking, a costbenefit analysis would offer solutions to manage this tension as a trade-off. But it seems that in current examples of social innovation, as in SCOs, this tension is instead accommodated by living with the two demands rather than choosing one over the other (Ospina and Saz-Carranza 2010). Regarding social innovation practices and processes, an interesting research challenge would be to analyze how (that is, through which leadership practices), amid scarcity, ways are found to move forward while at the same time honouring the need for inclusion. It is likely that keeping and achieving both aims is what will produce a real social transformation.

\subsection{CONCLUSIONS}

Leadership and social innovation, as research topics, share several common features. Both are fields of study that have been tackled by multiple and overlapping academic disciplines, such as management, economics, psychology, sociology and political science. Both have been studied with the aim of explaining similar phenomena, such as social change or community development. Finally, both have focused on the relationship between individuals, organizations and society.

Beyond these general similarities, important common points exist with respect to the theoretical approaches developed in both fields. For example, those perspectives that understand social innovation as entrepreneurial designing, producing and leading to market new ideas, services and processes to cope with social needs - dovetail with leadership theories that focus on the individual skills that foster the success of this kind of entrepreneurial innovation. Similarly, those approaches that define social innovation as more effective and efficient solutions to social problems than those that preceded them invoke managerial theories of leadership that focus on leaders' attempts to engineer effectiveness. Nevertheless, the changes western societies have witnessed during recent decades offer a context in which counterhegemonic understandings of social innovation and leadership are both claimed and needed. In these circumstances, where social needs are transformed and multiplied and where new responses are emerging from below, a key challenge is to understand not only how social change is taking place but also how it has and can be fostered. As we 
bring together theories of social innovation and relational leadership, new avenues open up in this direction.

Among the literature reviewed in this chapter, there are two recently developed bodies of theory that to some extent correspond to the postrecession context. On one hand, disruptive theories of social innovation may be useful for understanding socially innovative responses to the crisis, since these responses are characterized by the complexity of their social and geographical context and by the fostering of a disruptive shift in power relationships. On the other hand, constructionist theories of relational leadership could also be useful for understanding how social change happens through new collective and cooperative modes of selfmanagement. However, beyond the fact that both bodies of theory focus on social change processes, there are important substantive reasons to bring together these two interdisciplinary fields of study.

First, both theoretical bodies use a systemic and contextual approach. Disruptive theories of social innovation highlight the importance of context and path dependency to understand how social innovation practices emerge and may become processes of social change (Moulaert et al. 2010). Constructionist theories of relational leadership argue that leadership is intrinsically relational and social in nature, being rooted in particular contexts (Ospina and Hittleman 2011). For scholars of disruptive social innovation, the object of interest is the entire social ecology that enables the innovation process (Westley and Antadze 2010), while from a constructionist view leadership is relational and systemic as it emerges and manifests itself through relationships in particular contexts and cannot exist outside them (Ospina and Sorenson 2006).

Second, beyond their commonalities, the two bodies of theory are not mutually exclusive but rather complementary. Disruptive theories of social innovation pay little attention to (collective) capacities that enable successful processes of social innovation, while that is exactly what constructionist theories of relational leadership do. On the other hand, constructionist theories of relational leadership focus on strategic actions to build collective power, paying less attention to the social transformations achieved through this process, while that is one of the strengths of disruptive theories of social innovation.

Third, if disruptive theories of social innovation tend to be based on structural-contextual analysis and assume path-dependent dynamics, constructionist theories of relational leadership tend to assume (collective) agency as a driving force explaining how social change happens. As Light (2011) states, problems only can be solved if agents of change have the purpose and the perseverance necessary to confront the status quo; but social change must be understood as a complex breakthrough cycle with 
multiple (also contextual) drivers. Hence, bringing together both theoretical bodies would provide a broader understanding of the dynamics of social change today. From this point of view, far from being contradictory forces, agency and structure should be understood as playing complementary and dialectical roles (Moulaert et al. 2016).

Bringing together social innovation and relational theories of leadership is a novel contribution to social change studies. To the best of our knowledge, the only existing book that links social innovation and leadership is Social Innovation and Impact in Nonprofit Leadership, edited by HansenTurton and Torres (2014). However, their book differs from our research in the following ways: a) it is focused on the nonprofit sector, while we analyze social change from a cross-sectoral perspective; b) it understands social innovation as a form of entrepreneurialism, while our conception is more systemic, defining social innovation as a context-dependent process through which social needs are satisfied, citizens are empowered and social relations are transformed; and c) it uses a traditional leadership approach based on individual leaders and their managerial style, while we use a constructionist approach based on collective leadership practices.

In sum, new forms of social innovation are embedded in specific communities and characterized by different forms and degrees of institutionalization. Hence, the capacity of social innovation to foster effective social change depends on how these communities are connected, what their path dependencies are, the degree to which they possess or create collective capacity to produce long-term outcomes and finally, how those citizens can be effectively engaged in social innovation processes. In other words, local context and community leadership practices are both key elements to be considered in understanding social innovation processes today. At the same time, however, the current lexicon regarding leadership may be insufficient for describing today's world. We need a new conception of leadership derived from relational, collective, collaborative, democratic, horizontal and networked community dynamics; that is, a new conception of leadership more suited to the post-recession era. In the following chapters, we will address the theoretical and research challenges of integrating disruptive theories of social innovation and constructionist theories of relational leadership from different perspectives.

\section{NOTES}

1. Geographies of crises will be analyzed in depth in Chapter 2 .

2. A deeper framework on leadership theories will be offered in Chapter 4. 